\title{
Effect of culture filtrates of pathogenic and antagonistic fungi on seed germination of some economically important vegetables
}

\section{Shazia Parveen*, Abdul Hamid Wani and Mohd Yaqub Bhat}

Section of Mycology and Plant Pathology. Department of Botany. University of Kashmir. Kashmir - 190006. India.*Email: shahshazia442@gmail.com.

\begin{abstract}
The subject of present study was to check whether the pathogenic fungi that were associated with different rot diseases of fruits and vegetables and the antagonistic fungal species produce extracellular growth regulating substances. For this present study healthy seeds of four economically important crop plants, viz. Solanum lycopersicum, Brassica rapa, Raphanus sativus and Trigonella melongena were selected. The results showed that all the pathogenic fungi except Fusarium solani decrease the germination percentage of the all seeds. Solanum lycopersicum seed germination was completely inhibited by the culture filtrate of Trichothecium roseum and Alternaria alternata. Likewise, the culture filtrate of Penicillium expansum caused complete inhibition of the germination of Brassica rapa seeds. The culture filtrate of Fusarium solani was found to increase the germination percentage of all the seeds tested during the present study. Amongst the three Trichoderma spp., T. asperellum and T. harzianum culture filtrate effectively increases the seed germination percentage of all the seeds tested while the culture filtrate of $T$. viride have negative effect on the germination percentage of Solanum lycopersicum, Brassica rapa, and Raphanus sativus seeds. This stimulatory or inhibitory effect of the culture filtrates can be attributed to the presence of certain metabolites/substances that the test fungi have released in the medium. To identify the substances present and the nature of these substances further studies will be carried out.
\end{abstract}

Keywords: Antagonistic fungi; Culture filtrate; Pathogenic fungi; Seed germination.
Received

January 18, 2019

Accepted

February 13, 2019

Released

April 30, 2019

Full Text Article



ORCID

(ㄱ) 0000-0002-0086-2685 Shazia Parveen

(ㄷ) 0000-0002-6157-9656 Abdul Hamid Wani

(1) 0000-0002-0582-4813 Mohd Yaqub Bhat

\section{Introduction}

Fungal rot of fruits and vegetables is the predominant postharvest disease (Janisiewicz and Korsten 2002) and cause huge losses to the growers in terms of yield (Bhale 2011). Certain fungal pathogens also synthesize certain mycotoxins or metabolites on their hosts which are harmful to the consumers and restrict their growth (Roy et al., 1972; Alwakeel, 2013). These fungal metabolites are substances that are discharged by the fungal species during their metabolic processes. The metabolites can be aminoacids, phenols, terpenoids, plant growth regulators (Madhosing, 1995). 
Certain fungal genera like Aspergillus, Penicillium, Alternaria, Rhizoctonia produce mycotoxins and degrade the seed quality and their viability (Caster and Frederiksen, 1980). These toxins are known to suppress the germination and sprouting of several seeds (Roy et al., 1972; Kunwar et al., 1987). Strains of Trichoderma spp. used as biological agents are capable of increase in plant growth even in absence of pathogen. The application of Trichoderma causes increase in the germination, plant height, leaf area and dry weight (Lindsey and Baker, 1967; Inbar et al., 1996).

So the aim of the present study was to check the effect of extracellular metabolites produced by the pathogenic fungi and the antagonistic fungi on seed germination of some economically important vegetable plants.

\section{Materials and methods}

\section{Fungal isolates}

The fungal pathogens and the antagonistic fungi used during the present study were obtained from Section of Mycology and Plant Pathology, Department of Botany, University of Kashmir, Srinagar. The fungal pathogens, Trichothecium roseum, Aspergillus niger, Cladosporium herbarum, Alternaria alternata, Penicillium chrysogenum, Penicillium expansum and Fusarium solani were isolated from decayed fruits and were found to be the common postharvest rot causing fungal pathogens of fruits and vegetables (Parveen et al., 2013, 2014; Parveen and Wani, 2015). Three different Trichoderma spp., viz. T. harzianum, T. viride and T. asperellum were isolated from healthy fruits and were further identified from IARI, New Delhi.

\section{Preparation of culture filtrate}

The fungal organisms both pathogenic as well as antagonistic used in this study were grown in Richard's solution. $100 \mathrm{~mL}$ of Richard's solution was transferred to $250 \mathrm{ml}$ conical flasks and inoculated with fungal inoculum taken from the edge of growing hyphae of 7 days old culture grown on PDA medium. The flasks were incubated at 25 ${ }^{\circ} \mathrm{C} \pm 2{ }^{\circ} \mathrm{C}$ for 20 days. The mycelial mat was then removed by filtering through whatman's filter paper. The filtrate was then centrifuged to obtain a cell free culture filtrate. The filtrate was collected in presterilized conical flasks and used for further experiments.

\section{Effect of culture filtrate on seed germination of some vegetables}

The effect of culture filtrates of the fruit rot causing fungal pathogens and the antagonists was determined by their effect on seed germination. Healthy seeds of crop plants, viz. Solanum lycopersicum, Brassica rapa, Raphanus sativus and Trigonella melongena were selected and surface sterilized by $0.1 \%$ mercuric chloride and then by distilled water. Sterilized seeds were soaked in the culture filtrate for $24 \mathrm{~h}$. These were them removed from the culture filtrate and placed on moist filter paper in presterilized Petriplates. The petriplates were then sealed with parafilm and kept at room temperature. Seeds soaked in uninoculated liquid medium and distilled water served as control. 10 replicates were taken for each treatment. Percent germination of seeds was observed and recorded as under:

\section{Percent seed germination $=\frac{\text { Number of seeds germinated }}{\text { Total } \text { number of seeds }} \times 100$}




\section{Results}

The toxicity of the culture filtrates prepared from the isolated rot causing fungal pathogens and the biological control agents was tested against the seed germination of Solanum lycopersicum, Brassica rapa, Raphanus sativus and Trigonella melongena to check the effect of extracellular metabolites released by the fungus in the liquid culture medium. Amongst the fruit rot pathogenic fungi, the highest toxicity or least germination was found by the culture filtrate obtained from Trichothecium roseum, Alternaria alternata and Penicillium expansum (Table 1, Figure 1). This inhibition in germination can be attributed to certain metabolites which are produced by the fungal pathogens to restrict the germination of the seeds. Solanum lycopersicum seed germination was completely inhibited by the culture filtrate of Trichothecium roseum and Alternaria alternata. Likewise, the culture filtrate of Penicillium expansum caused complete inhibition of the germination of Brassica rapa seeds. Amongst the fruit rot fungal pathogens Fusarium solani was found to accelerate the germination of all the tested seeds.

Table 1. Effect of culture filtrates of isolated fungi on seed germination of different crop plants.

\begin{tabular}{|l|c|c|c|c|}
\hline \multirow{2}{*}{ Culture filtrate } & \multicolumn{4}{|c|}{ Seed germination (\%) } \\
\cline { 2 - 5 } & $\begin{array}{c}\text { Solanum } \\
\text { lycopersicum }\end{array}$ & $\begin{array}{c}\text { Brassica } \\
\text { rapa }\end{array}$ & $\begin{array}{c}\text { Raphanus } \\
\text { sativus }\end{array}$ & $\begin{array}{c}\text { Trigonella } \\
\text { melongena }\end{array}$ \\
\hline Trichothecium roseum & 0 & 10 & 20 & 50 \\
\hline Aspergillus niger & 10 & 10 & 50 & 60 \\
\hline Cladosporium herbarum & 10 & 10 & 40 & 70 \\
\hline Alternaria alternata & 0 & 0 & 30 & 60 \\
\hline Penicillium chrysogenum & 20 & 20 & 60 & 60 \\
\hline Penicillium expansum & 20 & 0 & 40 & 50 \\
\hline Fusarium solani & 50 & 70 & 100 & 100 \\
\hline Liquid culture & 30 & 60 & 80 & 100 \\
\hline Control (H, $\left.{ }_{2} \mathrm{O}\right)$ & 50 & 50 & 70 & 80 \\
\hline
\end{tabular}

The culture filtrate of the three antagonistic fungi that are used for the biological control studies, Trichoderma harzianum, Trichoderma viride and Trichoderma asperellum were also evaluated for the effect on the seed germination (Table 2, Figure 2). Amongst the three species, $T$. asperellum and $T$. harzianum culture filtrate were found to have stimulatory effect on seed germination and was found to cause increase in the seed germination percentage. Culture filtrate of $T$. viride cause inhibition in seed germination of $B$. rapa and $R$. sativus. Culture filtrate of all Trichoderma spp. were found to increase the seed germination percentage of Solanum lycopersicum and Trigonella melongena, whereas a negative effect was found on the germination percentage of B. rapa and R. sativus seeds by culture filtrate of $T$. viride. 


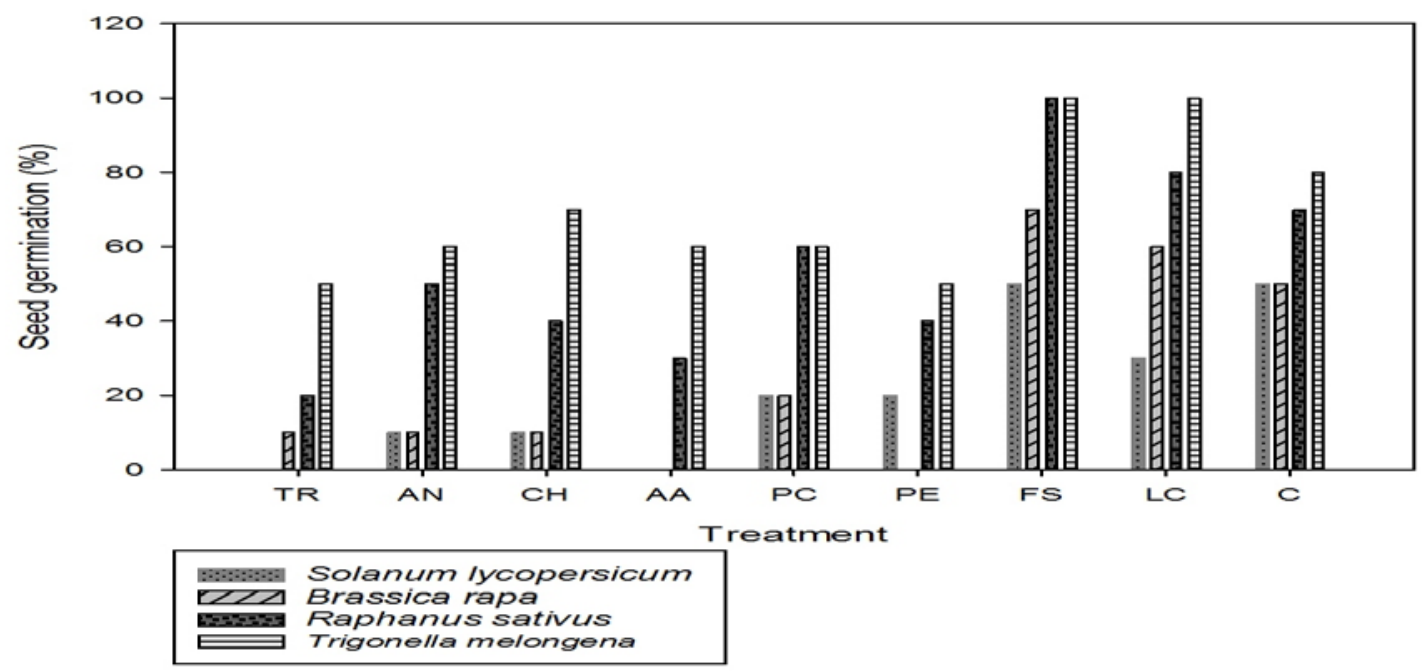

Figure 1. Germination percentage of different seed by treatment with different culture filtrates of pathogenic fungi. TR - Trichothecium roseum, AN - Aspergillus niger, $\mathrm{CH}$ - Cladosporium herbarum, AA - Alternaria alternata, PE - Penicillium chrysogenum, PC - Penicillium expansum, FS - Fusarium solani, LC - liquid culture control, C - Control (distilled $\mathrm{H}_{2} \mathrm{O}$ ).

Table 2. Effect of culture filtrates of antagonistic fungi on seed germination of different crop plants

\begin{tabular}{|l|c|c|c|c|}
\hline \multirow{2}{*}{ Culture filtrate } & \multicolumn{4}{|c|}{ Seed germination (\%) } \\
\cline { 2 - 5 } & $\begin{array}{c}\text { Solanum } \\
\text { lycopersicum }\end{array}$ & $\begin{array}{c}\text { Brassica } \\
\text { rapa }\end{array}$ & $\begin{array}{c}\text { Raphanus } \\
\text { sativus }\end{array}$ & $\begin{array}{c}\text { Trigonella } \\
\text { melongena }\end{array}$ \\
\hline Trichoderma harzianum & 50 & 60 & 80 & 90 \\
\hline Trichoderma viride & 40 & 30 & 50 & 100 \\
\hline Trichoderma asperellum & 60 & 40 & 90 & 100 \\
\hline Liquid culture & 30 & 60 & 80 & 100 \\
\hline Control $\left(\mathrm{H}_{2} \mathrm{O}\right)$ & 50 & 50 & 70 & 80 \\
\hline
\end{tabular}



Figure 2. Germination percentage of different seed treated with culture filtrate of antagonistic fungi. TH - Trichoderma harzianum, TV - Trichoderma viride, TA - Trichoderma asperellum, LC Liquid culture control, C- Control $\left(\mathrm{H}_{2} \mathrm{O}\right)$. 


\section{Discussion}

During the present study, it was reported that the culture filtrates of the pathogenic fungi caused inhibition in germination of all the tested seeds, viz. Solanum lycopersicum, Brassica rapa, Raphanus sativus and Trigonella melongena. Similar results were obtained by Haikal (2008), Jalander and Gachande (2012), Garuba et al. (2014). Kunwar and Mehrotra (1988) studied the effect of culture filtrate of storage fungi on germination and sprouting of wheat grains and reported that culture filtrate of all the fungal species screened inhibited germination and sprouting of grains, with complete inhibition by culture filtrate of Aspergillus clavatus and Penicillium urticae. Umechuruba and Nwachukwu (1997) reported that Aspergillus niger, Aspergillus flavus, Fusarium moniliforme and Penicillium sp. produce various metabolites that are known to reduce the seed germination percentage and seedling development of bean seeds. Jalander and Gachande (2012) reported that the culture filtrate of Aspergillus niger inhibit seed germination of several pulses and cereals. Haikal (2008) reported that the culture filtrates of Aspergillus niger, Fusarium culmorium, Penicillium sp. and Rhizoctonia solani inhibited seed germination and seedling development of soyabean, representing that these fungi produced some toxic substances in the culture media in which they were grown, inhibiting or reducing the germination percentage of seeds. Inhibition or stimulation of seed germination may be related to the certain substances that these fungi produce extracellularly, that can regulate the activity of hydrolytic enzymes (Negi et al., 1983).

Present study also depicted that the culture filtrate of antagonistic fungi like Trichoderma harzianum, Trichoderma viride and Trichoderma asperellum have a pronounced effect on the seed germination of Solanum lycopersicum, Brassica rapa, Raphanus sativus and Trigonella melongena. T. harzianum and T. asperellum effectively increased the seed germination percentage of all the seeds tested. Similar results were reported by Gupta and Sharma (1995), Celar and Valic (2005). Cole and Zvenyika (1988) reported that seeds of few plants like tobacco grew better when $T$. harzianum was added to the soil. Gupta and Sharma (1995) reported that the culture filtrate of Trichoderma spp. increased the seed germination of black gram.

Reduction in the seed germination by the culture filtrate can be attributed to the presence of certain mycotoxins, enzymes released by the respective fungal species (Karman and Malavuly, 2005). Antagonistic fungi used may directly or in directly influence the growth and development of higher plants. In previous studies, it was reported that the antagonistic fungi have stimulating effect on plants (Chang et al., 1986) with very little negative effects reported only when large amount of inoculum of antagonistic fungi is used (Kohl and Schlosser, 1989).

\section{Conflicts of interest}

Authors declare that they have no conflict of interests.

\section{References}

Alwakeel, S. S. Molecular identification of isolated fungi from stored apples in Riyadh, Saudi Arabia. Saudi Journal of Biological Sciences, v. 20, p. 311-317, 2013.

Bhale, U. N. Survey of market storage diseases of some important fruits of Osmannabad district, India. Science Research Reporter, v. 1, no. 2, p. 88-91, 2011.

Caster, L.; Frederikson, R. A. Fusarium head blight, occurrence of effects on sorghum yield and grain characteristics in Texas. Journal of Plant Disease, v. 64, p. 1017-1019, 1980.

Celar, F.; Valic, N. Effects of Trichoderma spp. and Gliocladium roseum culture filtrate on 
seed germination of vegetable and Maize. Journal of Plant Diseases and Protection, v. 112, no. 4, p. 343-350, 2005.

Chang, Y. C.; Baker, R.; Kleifeld, O.; Chet, I. Increased growth of plants in the presence of the biological control agent Trichoderma harzianum. Plant Disease, v. 70, p. 145-148, 1986.

Cole, J. S.; Zvenyika, Z. Integrated control of Rhizoctonia solani and Fusarium solani in tobacco transplants with Trichoderma harzianum and Triadimenol. Plant Pathology, v. 37, p. 271-277, 1988.

Garuba, T.; Abdulrahaman, A. A.; Olahan, G. S.; Abdulkareem, K. A.; Amadi, J. E. Effects of fungal filtrates on seed germination and leaf anatomy of maize seedlings (Zea mays L., Poaceae). Journal of Applied Sciences and Environmental Management, v. 18, no. 4, p. 662-667, 2014.

Gupta, 0.; Sharma, N. D. Effect of fungal metabolites on seed germination and root length of black gram (Phaseolus mungo L.). Legume Research, v. 18, p. 64-66, 1995.

Haikal, N. Z. Effect of filtrates of pathogenic fungi of soyabean on seed germination and seedling parameters. Journal of Applied Sciences Research, v. 4, no. 1, p. 48-52, 2008.

Inber, J.; Mendez, I.; Chet, I. Hyphal interaction between Trichoderma harzianum and Sclerotinia sclerotium and its role in biological control. Soil Biology and Biochemistry, v. 28, p. 757-763, 1996.

Jalander, V. Gachande, B. D. Effect of fungal metabolites of some rhizospheric soil fungi on seed germination and seedling growth of some pulses and cereals. Science Research Reporter, v. 2, no. 3, p. 265-267, 2012.

Janisiewicz, W. J.; Korsten, L. Biological Control of post-harvest diseases of fruits. Annual Review of Phytopathology, v. 40, p. 411-441, 2002.

Karman, M.; Malavuly, M. Heavy metals and macro elements in some macro fungi of national park Frushkagora (Serbia). Proceeding of the 8th ISIRR-International Symposium on Interdisciplinary Regional Research, 2005. p. 1-10.
Kohl, J.; Schlosser, E. Effect of Trichoderma spp. on seedlings of sugar beet during the biological control of pathogens. Mededelingen van de Faculteit Landbouwwetenschappen, Rijksuniversiteit Gent, v. 54/2b, p. 707-714, 1987.

Kunwar, I. K.; Mehrotra, B. S. Effect of culture filtrates of storage fungi on germination and sprouting of wheat grains. Proceedings of Indian National Science Academy, v. B54, no. 6, p. 399-400, 1988.

Kunwar, I. K.; Halfon-Meiri, A.; Manandhar, J. B.; Sinclair, J. B. Possible phytotoxic metabolites in the culture filtrates of Diaporthe phaseolarum var. sojae. Mycopathologia, v. 99, p. 71-79, 1987.

Lindsey, D. L.; Baker, R. Effect of certain fungi on dwarf tomatoes grown under gnotobiotic conditions. Phytopathology, v. 57, p. 12621263, 1967.

Madhosing, C. Relative wilt-inducing capacity of the culture filtrates of isolates of Fusarium oxysporum f. sp. radicis-lycopersici, the tomato crown and root rot pathogen. Journal of Phytopathology, v. 4, p. 193-198, 1995.

Negi, H. C. S.; Jain, S. K.; Singh, R. V. Seed dormancy in radish. Seed Research, v. 11, p. 60-62, 1983.

Parveen, S.; Wani, A. H. In vitro efficacy of some fungicides and plant extracts on Mucor piriformis Fisher causing postharvest rot of peach in Kashmir Valley. Trends in Biosciences, v. 8, no. 3, p. 620-627, 2015.

Parveen, S.; Wani, A. H.; Bhat, M. Y.; Pala, S. A.; Ganie, A. A. Biology and management of Aspergillus niger Van Tiegh. causing black mold rot of pear (Pyrus communis L.) in Kashmir Valley, India. International Journal of Advanced Research, v. 2, no. 6, p. 24-34, 2014.

Parveen, S.; Wani, A. H.; Ganie, A. A.; Pala, S. A.; Mir, R. A. Antifungal activity if some plant extracts on some pathogenic fungi. Archives of Phytopathology and Plant Protection, v. 47, no. $3, \quad$ p. $279-284, \quad 2013$. https://doi.org/10.1080/03235408.2013.80 8857 
Roy, R. Y.; Dwivedi, R. S.; Gupta, S. Effect of rhizospheric mycoflora on the growth of Trigonella foenum- graceum. Proceedings of National Academy of Science of India, v. 42 , p. $105-110,1972$.

Umecharuba, G. I.; Nwachukwa, E. O. The effect of filtrate of seed borne fungi of African yam bean on seed germination and seedling development. Global Journal of Pure and Applied Sciences, v. 3, p. 165-175, 1997. 